\title{
Formation of Nanocrystallized Structure in Worn Surface Layer of T10 Steel against 20CrMnTi Steel during Dry Rubbing
}

\author{
Xin Wang, ${ }^{1,2}$ Xicheng Wei, ${ }^{2}$ Jing Zhang, ${ }^{1,2}$ Rongbin Li, ${ }^{1}$ Meng Hua, ${ }^{3}$ and Wurong Wang ${ }^{2}$ \\ ${ }^{1}$ School of Mechanical Engineering, Shanghai Dian Ji University, 1350 Ganlan Road, Shanghai 201406, China \\ ${ }^{2}$ School of Materials Science and Engineering, Shanghai University, 149 Yanchang Road, Shanghai 200072, China \\ ${ }^{3}$ MBE Department, City University of Hong Kong, 83 Tat Chee Avenue, Kowloon Tong, Kowloon, Hong Kong \\ Correspondence should be addressed to Rongbin Li; lirb@sdju.edu.cn
}

Received 30 January 2015; Revised 28 April 2015; Accepted 19 May 2015

Academic Editor: Hanadi Salem

Copyright (C) 2016 Xin Wang et al. This is an open access article distributed under the Creative Commons Attribution License, which permits unrestricted use, distribution, and reproduction in any medium, provided the original work is properly cited.

T10 steel slid against 20CrMnTi steel on a pin-on-disc wear test rig. Optical Microscope (OM), scanning electron microscope (SEM), and High Resolution Transmission Electron Microscope (HRTEM) methods were used to analyze the microstructures in the worn surface layers. The microstructures in the worn surface layers of pins and discs were all severely plastically deformed. Furthermore, the ultrafine and even nanoferrite structure $(10 \mathrm{~nm}$ to $100 \mathrm{~nm}$ ) was observed when the normal load reached $60 \mathrm{~N}$. The mechanism of forming nanocrystalline structure in the sliding friction induced deformation layer (SFIDL) was elucidated as the result of the simultaneous and recursive actions of (i) severe shear deformation and (ii) friction heat on the contact surface.

\section{Introduction}

Nanocrystalline materials show extraordinarily high hardness and/or yield strength, so some metal engineering scientists have paid attention to them [1-3]. When the grain size decreased to the nanometer level, the nanocrystalline metals have the distinctive mechanical properties in comparison to their coarse-grained counterparts, resulting in the attractive application prospects [4-6]. The revealing of the subsurface structure evolution is quite useful in understanding the friction and wear behavior of crystalline materials. Therefore, many scholars made strenuous efforts to research the worn surface microstructural evolutions of the ductile materials, such as aluminum [7], magnesium [1], and copper alloys [8].

Undoubtedly, to study evolution of the microstructure in sliding surface layer of carbon steel with test conditions is beneficial for one to understand and optimize the surface properties. Furthermore, the researches on the evolution of microstructure can explore the possible modification techniques to enhance service lifetime of the parts. Unfortunately, the limited research has been carried out on the formation of carbon steel ultrafine structure induced by dry sliding subsurface deformation.
In this study, the friction and wear properties of normalized T10 steel pin against quenched and tempered 20CrMnTi steel disc were conducted on a pin-on-disc wear test rig. The microstructural evolution in the sliding friction induced deformation layer (SFIDL) was analyzed. The possible mechanism of forming ferrite ultrarefined structure in the sliding friction induced deformation layer (SFIDL) was elucidated.

\section{Methods}

2.1. Materials and Wear Test. The pin was made of T10 steel containing $0.98 \% \mathrm{C}, 0.40 \% \mathrm{Mn}, 0.35 \% \mathrm{Si}, 0.011 \% \mathrm{~S}, 0.013 \% \mathrm{P}$, and balance $\mathrm{Fe}$, and the disc was made of 20CrMnTi steel containing $0.2 \% \mathrm{C}, 1.2 \% \mathrm{Cr}, 0.1 \% \mathrm{Ti}, 0.2 \% \mathrm{Si}, 0.25 \% \mathrm{Cu}, 0.04 \% \mathrm{~S}$, $0.04 \% \mathrm{P}, 0.95 \% \mathrm{Mn}$, and balance Fe, respectively. Their hardness of pin and disc specimens was about $180 \mathrm{HB}$ and $357 \mathrm{HB}$, respectively. Their surface roughness of the pin and disc specimens was $\mathrm{Ra} 0.03 \sim 0.09 \mu \mathrm{m}$ and $\mathrm{Ra} 0.05 \sim 0.1 \mu \mathrm{m}$, respectively.

The MM-W1 disc-on-pin wear test rig was used in a laboratory environment to carry out the dry sliding friction test. The sliding speed was $0.29 \mathrm{~m} / \mathrm{s}$, the test time was $7200 \mathrm{~s}$, and the selected normal loads were $40 \mathrm{~N}, 50 \mathrm{~N}$, and $60 \mathrm{~N}$, 
respectively. The pin and disc specimens after test were crosssectioned cut.

\subsection{Observation of Worn Surface and Friction Induced Surface} Layer. Metallographic specimens were EDM-wire-cut along the sliding direction of slid SFIDLs, which were then coolinlayed with tooth acrylic resin, grinded and polished with $\mathrm{SiC}$ sand paper, and then etched with a $4 \%$ nitric acid alcohol solution. Removed the tooth acrylic resin and ultrasonically cleaned via acetone solution. The worn surfaces were protected by electroless Ni plating. The so-prepared specimens were subsequently analyzed by a VHX-600 Optical Microscope (OM) and a HITACHI S-570 scanning electron microscope (SEM) with a $20 \mathrm{kV}$ energy spectrum.

To analyze whether there was any possible structure refinement on the utmost top of the slid surface, individual $0.5 \mathrm{~mm}$ thick slices were wire-cut along the depth direction, which were carefully thinned to a thickness in range of $30 \mu \mathrm{m} \sim 50 \mu \mathrm{m}$ by gradually grinding off the slices from their nonslid surface. Transparent tape was used to protect the worn surface of the thinned specimens which were then punch-pressed into $3 \mathrm{~mm}$ diameter wafers. After singlejet electropolishing and ion thinning for 30 minutes, the specimens were analyzed via a JEM-2010 High Resolution Transmission Electron Microscope (HRTEM) equipped with a Gatan Image Filter (GIF) and selected area electron diffraction (SAED).

\section{Results and Discussion}

3.1. Worn Surface Layer. OM images of longitudinal cross section of T10 pins and 20CrMnTi discs were shown in Figure 1. The morphologies of SFIDLs were plastically deformed and inclined to the sliding direction in both T10 pins and 20CrMnTi discs. Beneath the worn surfaces, the ferrite and pearlite were elongated (Figures 1(a)-1(c)) and the martensite was also inclined to the sliding direction (Figures 1(d)-1(f)), which indicated that the severe plastic strain occurred as a result of friction shear stress [9]. With increased loads, higher frictional force produced larger plastic strain and greater extent of plastic deformation.

In comparison of $\mathrm{T} 10$ pins and $20 \mathrm{CrMnTi}$ discs, the morphology of subsurface layer clearly revealed that the plastic deformation degrees of pin exceeded that of disc in the sliding direction. It might be contributed to the higher initial hardness of 20CrMnTi disc, which implied that the strong strain hardening was produced and the hardness was enhanced when the normal load reached $60 \mathrm{~N}$ [9].

To better understand the SFIDL microstructures of pins and discs, cross sections' SEM images were shown in Figure 2. According to the method proposed by Rice et al., [10] the SFIDLs can be divided into two zones, referred to as Mechanically Mixed Layer (MML) and Plastic Deformation Layer (PDL). (i) Wang et al. [11] found that $0.45 \%{ }^{\circ} \mathrm{C}$ steels have a high density of grain boundaries and lattice dislocations in a highly nonequilibrium state in the MML, when they are rubbing against the tin alloy, which is consistent with the structure characterized by Figure 2(a). Obviously, owing to the composite effect of shear and squeezing, the materials transferred between two mating MMLs during dry rubbing progress. Simultaneously, the MML was gradually heaped up and accumulated, eventually leading to the microcracks propagated parallel to the sliding direction during the rubbing (Figure 2(a)). (ii) Considerable plastic deformation and repetitive friction heat promoted the formation of the PDL during drastically rubbing process. The pressure and the tangential shear force tended to plastically deform the near surface material. The lamellar pearlites (Figure 2(a)) and the martensites (Figure 2(b)) were reoriented or even fractured along the sliding direction, which attributed to their ductility and brittleness. The appearance of clear plastic flow lines propagates from the worn surface to the matrix, which have been similarly described in [12].

Comparing the microstructural evolution of T10 pin with 20CrMnTi disc, the plastic deformation of 20CrMnTi disc was smaller than T10 pin (Figure 2(b)). It is worthy of notice that the harder tribopair emerges to be deformed more slightly than the softer tribopair during the rubbing process. Such finding obviously was confirmed and substantiated by the findings of Venkataraman and Sundararajan [13] and Viáfara and Sinatora [14].

\subsection{Ultrarefinement and Nanocrystallization in Worn Surface} Layer. Figure 3 is the TEM dark field images and SAED patterns of the T10 steel pins worn surface layers under $40 \mathrm{~N}$, $50 \mathrm{~N}$, and $60 \mathrm{~N}$. The SAED pattern in Figure 3(a) reveals some ultrafine grains with random orientation in the worn surface layer. The SAED pattern in Figure 3(b) shows nearly continuous bcc ferrite rings, and the cementite ring is not found. It can be inferred that the cementite was possibly dissolved into the matrix or worn off. The SAED pattern in Figure 3(c) indicates that the microstructure was randomly oriented bcc grains without any cementite rings, which suggests that the cementite nearly decomposed completely. In addition, some smaller and more uniform grains in the worn surface layer were observed. Figure 3(d) shows the HRTEM image of the nanostructure ferrite in T10 pin under $60 \mathrm{~N}$. The nearly equiaxed ultrafine structure, whose size of nanostructure was less than $10 \mathrm{~nm}$, containing formed dislocations and some lattice distortions accommodating at the grain boundaries, could be seen in Figure 3(d). Ivanisenko et al. [15] observed ultrafine ferrite grains in the pearlitic steel via mechanical milling, which was very similar to this research.

The higher normal load leads to bigger shear stress and thus larger plastic deformation, resulting in ultrafine grain and sharper grain boundaries. Similar decomposition phenomena of ferrite nanocrystallization under various plastic deformation processes have been reported, such as surface mechanical attrition on tool steel $[16,17]$, ball drop test on eutectoid steels [5], and drill holes on steel [18]. Todaka et al. [5] suggested that the dissolution of cementite is always accompanied by the decomposition of pearlite colonies and ultrarefinement of ferrite. Therefore, the observed ferrite nanocrystalline in the present study may be the results of the ferrite nanocrystallization via severe shear deformation [19]. 


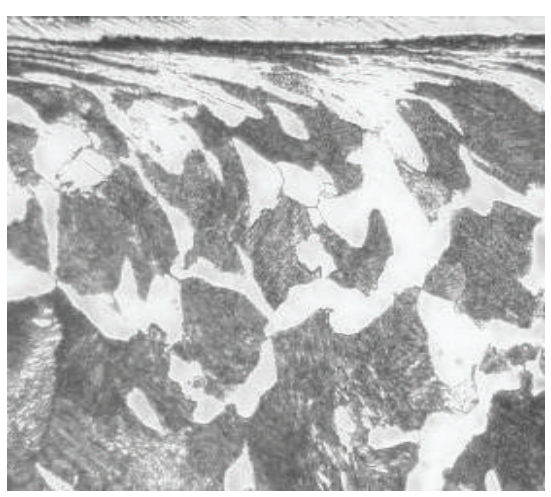

(a)

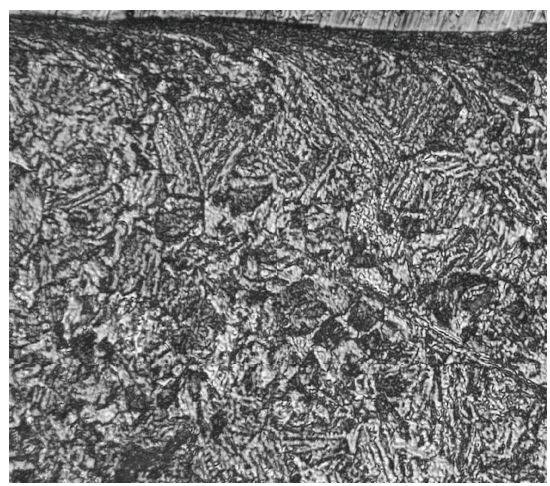

(d)

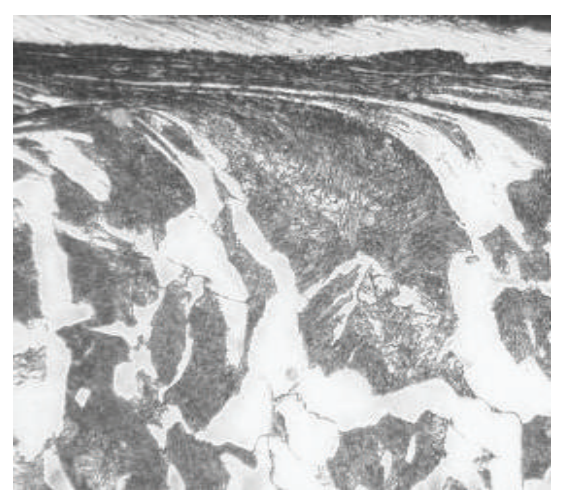

(b)

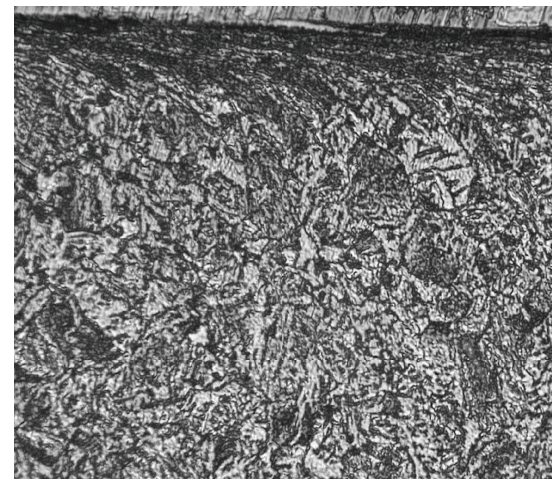

(e)

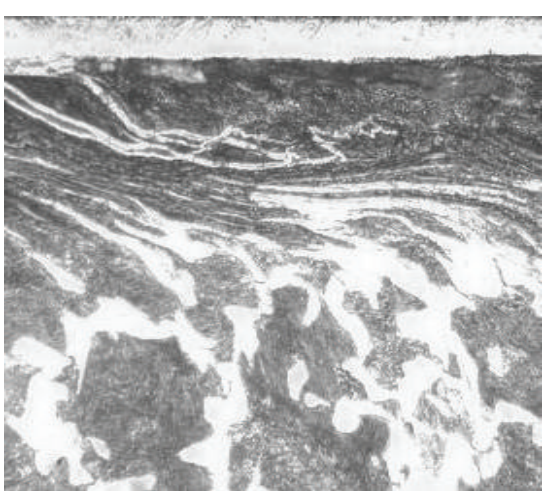

(c)

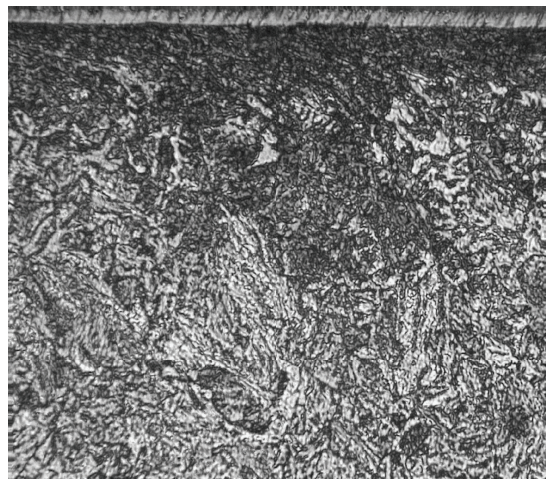

(f)

FIGURE 1: OM micrographs of longitudinal cross section of (a) T10 steel pin under $40 \mathrm{~N}$, (b) T10 steel pin under $50 \mathrm{~N}$, (c) T10 steel pin under $60 \mathrm{~N}$ [9], (d) 20CrMnTi steel disc under $40 \mathrm{~N}$, (e) 20CrMnTi steel disc under $50 \mathrm{~N}$, and (f) 20CrMnTi steel disc under $60 \mathrm{~N}$ [9].

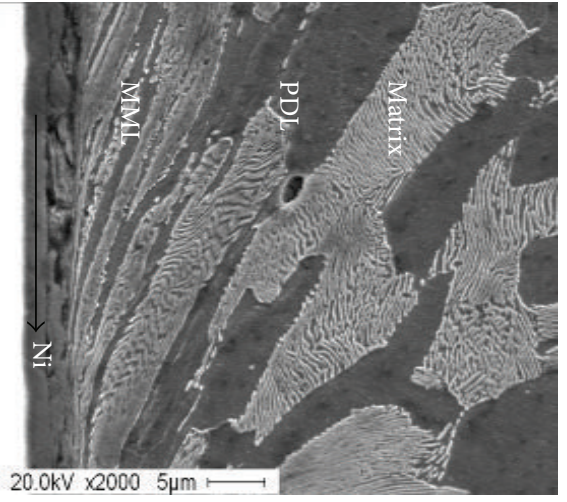

(a)

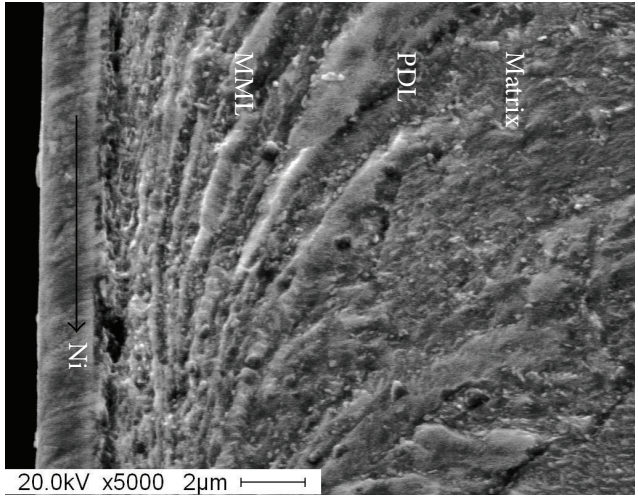

(b)

FIgURE 2: SEM images of worn surface layer of (a) T10 steel pin [9] and (b) 20CrMnTi steel disc.

At present, two possible mechanisms for explaining the ultrafine structure formation exist induced by sliding friction.

(i) The effect of severe shear deformation in the worn surface induced ultrafine structure formation. Rigney et al. [20-22] insisted that the ultrafine structure could be formed when the strain is high enough during the rubbing process. Obviously, the plastic shear flowing of material containing high fractions of low-angle subgrain boundaries with high densities of misfit dislocation entanglement located at these subgrain boundaries in the worn surface layer induces the formation of nanostructure. Ni et al. [23] revealed that grain refinement occurred by dislocation rearrangements, which was likely to happen via grain rotation and the formation of coarser grains under high strains during the deformation process. Sadykov et al. [24] confirmed that the ferrite grains could be ultrarefined up to nanometer scale by dry sliding 


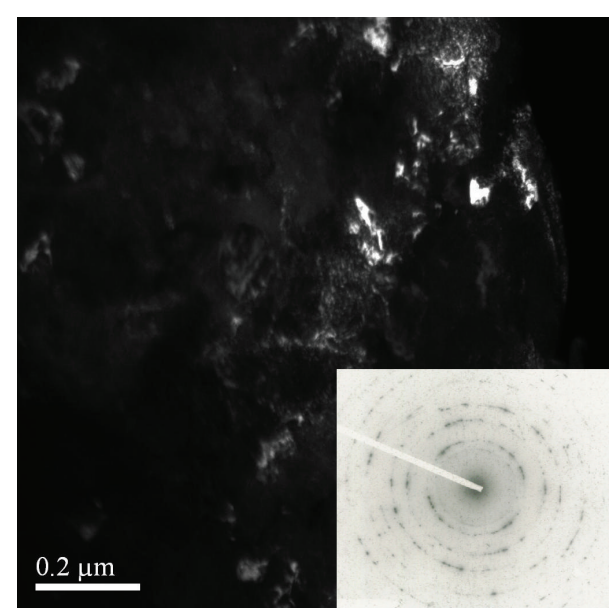

(a)

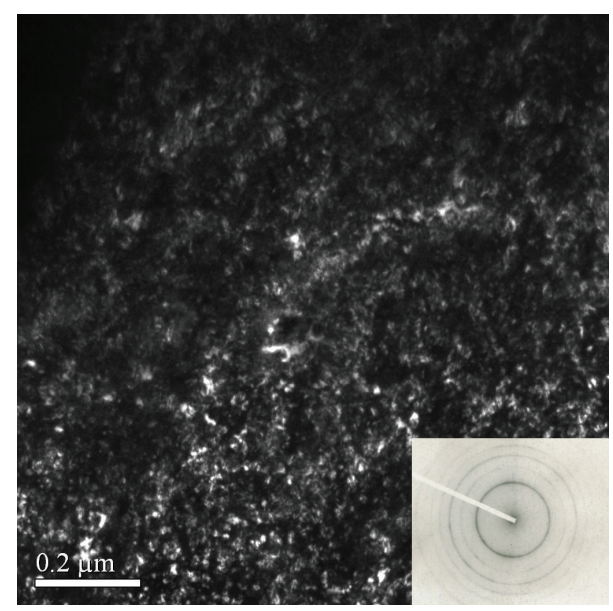

(c)

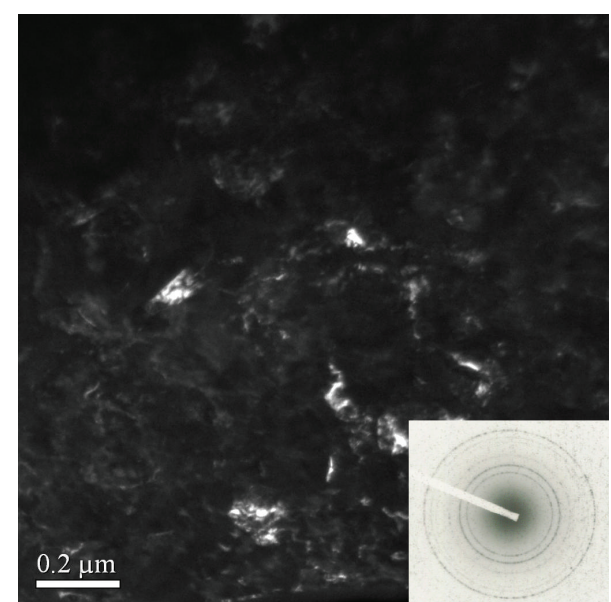

(b)

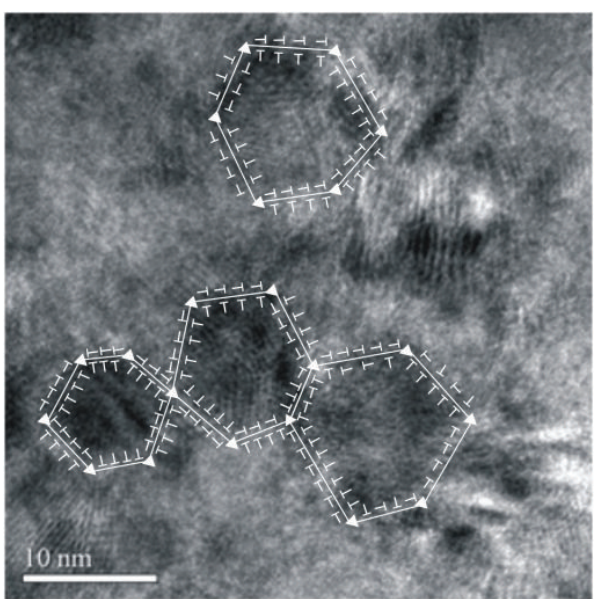

(d)

FIGURE 3: TEM DF images with diffraction patterns of worn surface layer of T10 steel pins under (a) $40 \mathrm{~N}$, (b) $50 \mathrm{~N}$, and (c) $60 \mathrm{~N}$ [9] and (d) HRTEM image of T10 steel pin under $60 \mathrm{~N}$.

friction at high load. Kato et al. [25] suggested that the shear deformation significantly increased the equivalent strain and promoted grain refinement.

(ii) The recrystallization was due to considerable friction heat. Wei et al. [26] considered that a large amount of friction heat agglomerated during dry rubbing process, which has a great influence on the microstructural evolution of near surface layer. Wang et al. [27, 28] verified that the flash temperature on the contact surfaces could reach $1000^{\circ} \mathrm{C}$ or even higher via the method of finite element analysis. In addition, the friction pair was undergoing temperature cycles, generating considerable heat stress during dry sliding process for the present experimental contact condition, which also accelerated plastic deformation of subsurface layer [28]. Owing to the higher temperature, the surface layer of pin would be softened and worn, leading to the formation of fresh surface and direct contact [29].

Therefore, it is certain that the observed ultrafine and even nanocrystalline ferrite on the T10 pin worn surface appeared to be the result of joint action of two mechanisms stated above. The ultrafine structure in the worn surface layer formed via the simultaneous and recursive actions of (i) severe shear deformation and (ii) friction heat on the contact surface.

\section{Conclusions}

Based on the experimental results discussed above, there are three conclusions obtained as follows.

(1) The T10 steel pin and 20CrMnTi steel disc specimens were both formed by the SFIDLs microstructures, and the clear plastic flow lines propagating from the worn surface to the matrix were observed.

(2) When the normal load reached $60 \mathrm{~N}$, the ultrafine and even nanocrystalline ferrite was formed in the worn surface of T10 steel pin, whose structure size was in the range of $10 \mathrm{~nm}$ to $100 \mathrm{~nm}$. 
(3) The formation mechanism of nanoferrite structure was considered to be the results of severe plastic deformation and friction heat induced by dry sliding friction.

\section{Conflict of Interests}

The authors declare that there is no conflict of interests regarding the publication of this paper.

\section{Acknowledgments}

This work was supported by the Outstanding Young Teachers' Special Funding of Shanghai Municipal Education Commission (ZZSDJ14007), the Scientific Research Innovation Project of Shanghai Municipal Education Commission (15ZZ104), the Science and Technology Sail Plan of Shanghai Science and Technology Commission (15YF1404400), and National Natural Science Foundation of China (Grant no. 51475280).

\section{References}

[1] H. Q. Sun, Y. N. Shi, and M.-X. Zhang, "Sliding wear-induced microstructure evolution of nanocrystalline and coarse-grained AZ91D Mg alloy," Wear, vol. 266, no. 7-8, pp. 666-670, 2009.

[2] J. B. Singh, J. G. Wen, and P. Bellon, "Plastic strain-induced grain refinement in the nanometer scale in a Mg alloy," Acta Materialia, vol. 56, pp. 3053-3064, 2008.

[3] D. M. Ba, S. N. Ma, F. J. Meng, and C. Q. Li, "Friction and wear behaviors of nanocrystalline surface layer of chrome-silicon alloy steel," Surface and Coatings Technology, vol. 202, no. 2, pp. 254-260, 2007.

[4] A. Kolubaev, S. Tarasov, O. Sizova, and E. Kolubaev, "Scaledependent subsurface deformation of metallic materials in sliding," Tribology International, vol. 43, no. 4, pp. 695-699, 2010.

[5] Y. Todaka, M. Umemoto, S. Tanaka, and K. Tsuchiya, "Formation of nanocrystalline structure at the surface of drill hole in steel," Materials Transactions, vol. 45, no. 7, pp. 2209-2213, 2004.

[6] M. Umemoto, Y. Todaka, and K. Tsuchiya, "Formation of nanocrystalline structure in steels by air blast shot peening," Materials Transactions, vol. 44, no. 7, pp. 1488-1493, 2003.

[7] C. Mallikarjuna, S. M. Shashidhara, U. S. Mallik, and K. I. Parashivamurthy, "Grain refinement and wear properties evaluation of aluminum alloy 2014 matrix- $\mathrm{TiB}_{2}$ in-situ composites," Materials \& Design, vol. 32, no. 6, pp. 3554-3559, 2011.

[8] A. Singh, M. Dao, L. Lu, and S. Suresh, "Deformation, structural changes and damage evolution in nanotwinned copper under repeated frictional contact sliding," Acta Materialia, vol. 59, no. 19, pp. 7311-7324, 2011.

[9] X. Wang, R.-B. Li, and J. Zhang, "Microstructural evolution in worn surface layer of T10 against 20CrMnTi steels after dry sliding friction," Applied Mechanics and Materials, vol. 692, pp. 282-287, 2014.

[10] S. L. Rice, H. Nowotny, and S. F. Wayne, "A survey of the development of subsurface zones in the wear of materials," Key Engineering Materials, vol. 33, pp. 77-100, 1989.

[11] X. Wang, D. Mao, X. Wei, J. Li, H. Meng, and W. Wang, "Sliding friction induced atom diffusion in the deformation layer of
0.45\% C steel rubbed against Tin alloy,' Tribology International, vol. 64, pp. 128-134, 2013.

[12] X. Wang, D. Mao, X. Wei, and W. Wang, "Cr atom diffusion in tribolayer T10 steel induced by dry sliding against 20CrMnTi steel," Applied Surface Science, vol. 270, pp. 145-149, 2013.

[13] B. Venkataraman and G. Sundararajan, "Correlation between the characteristics of the mechanically mixed layer and wear behaviour of aluminium, Al-7075 alloy and Al-MMCs," Wear, vol. 245, no. 1-2, pp. 22-38, 2000.

[14] C. C. Viáfara and A. Sinatora, "Influence of hardness of the harder body on wear regime transition in a sliding pair of steels," Wear, vol. 267, no. 1-4, pp. 425-432, 2009.

[15] Y. Ivanisenko, W. Lojkowski, R. Z. Valiev, and H.-J. Fecht, "The mechanism of formation of nanostructure and dissolution of cementite in a pearlitic steel during high pressure torsion," Acta Materialia, vol. 51, no. 18, pp. 5555-5570, 2003.

[16] S. D. Lu, Z. B. Wang, and K. Lu, "Enhanced chromizing kinetics of tool steel by means of surface mechanical attrition treatment," Materials Science and Engineering A, vol. 527, no. 4-5, pp. 9951002,2010

[17] S. D. Lu, Z. B. Wang, and K. Lu, "Strain-induced microstructure refinement in a tool steel subjected to surface mechanical attrition treatment," Journal of Materials Science \& Technology, vol. 26, no. 3, pp. 258-263, 2010.

[18] S. Ohsaki, K. Hono, H. Hidaka, and S. Takaki, "Characterization of nanocrystalline ferrite produced by mechanical milling of pearlitic steel," Scripta Materialia, vol. 52, no. 4, pp. 271-276, 2005.

[19] D. M. Ba, S. N. Ma, F. J. Meng, and C. Q. Li, "Friction and wear behaviors of nanocrystalline surface layer of chrome-silicon alloy steel," Surface and Coatings Technology, vol. 202, no. 2, pp. 254-260, 2007.

[20] D. A. Hughes, D. B. Dawson, J. S. Korellls, and L. I. Weingarten, "Near surface microstructures developing under large sliding loads," Journal of Materials Engineering and Performance, vol. 3, no. 4, pp. 459-475, 1994.

[21] D. A. Rigney, "Large strains associated with sliding contact of metals," Materials Research Innovations, vol. 1, no. 4, pp. 231234, 1998.

[22] D. A. Rigney, "Transfer, mixing and associated chemical and mechanical processes during the sliding of ductile materials," Wear, vol. 245, no. 1-2, pp. 1-9, 2000.

[23] S. Ni, Y. B. Wang, X. Z. Liao et al., "Grain growth and dislocation density evolution in a nanocrystalline Ni-Fe alloy induced by high-pressure torsion," Scripta Materialia, vol. 64, no. 4, pp. 327-330, 2011.

[24] F. A. Sadykov, N. P. Barykin, and I. R. Aslanyan, "Wear of copper and its alloys with submicrocrystalline structure," Wear, vol. 225-229, no. I, pp. 649-655, 1999.

[25] H. Kato, M. Sasase, and N. Suiya, "Friction-induced ultra-fine and nanocrystalline structures on metal surfaces in dry sliding," Tribology International, vol. 43, no. 5-6, pp. 925-928, 2010.

[26] X. Wei, M. Hua, Z. Xue, Z. Gao, and J. Li, "Evolution of frictioninduced microstructure of SUS 304 meta-stable austenitic stainless steel and its influence on wear behavior," Wear, vol. 267, no. 9-10, pp. 1386-1392, 2009.

[27] X. Wang, X. Wei, X. Hong, J. Yang, and W. Wang, "Formation of sliding friction-induced deformation layer with nanocrystalline structure in T10 steel against 20CrMnTi steel," Applied Surface Science, vol. 280, pp. 381-387, 2013. 
[28] X. Wang, X. Yang, Z. Cheng, W. Wang, and X. Wei, "Atomic diffusion of gradient ultrafine structured surface layer produced by T10 steel rubbing against 20CrMnTi steel," Wear, vol. 304, no. 1-2, pp. 118-125, 2013.

[29] D. Mao, X. Wang, W. Wang, and X. Wei, "Effect of boronizing on the dry sliding wear behavior of DC53/0.45 mass\% C steel pairs," Surface and Coatings Technology, vol. 207, pp. 190-195, 2012. 

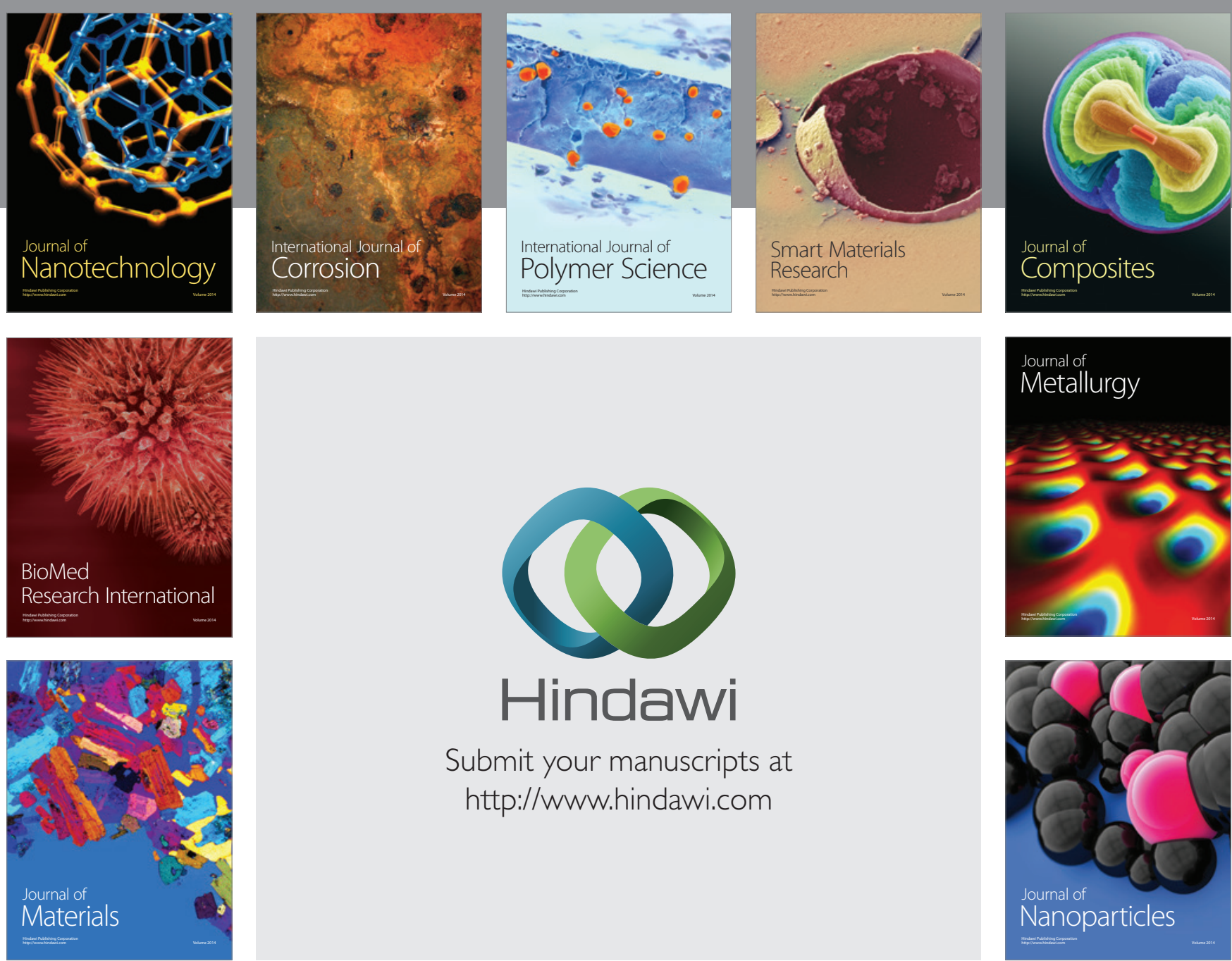

\section{Hindawi}

Submit your manuscripts at

http://www.hindawi.com

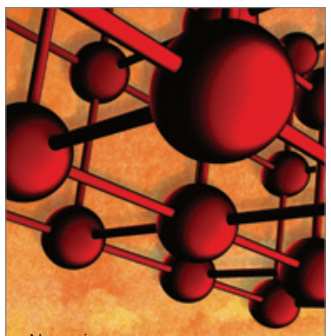

Materials Science and Engineering
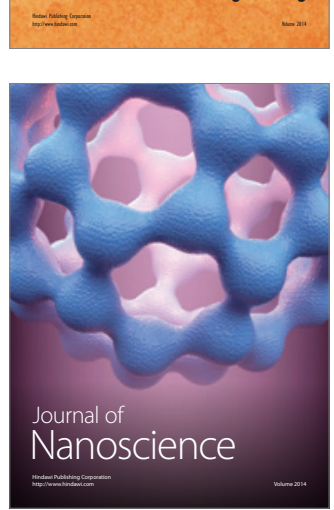
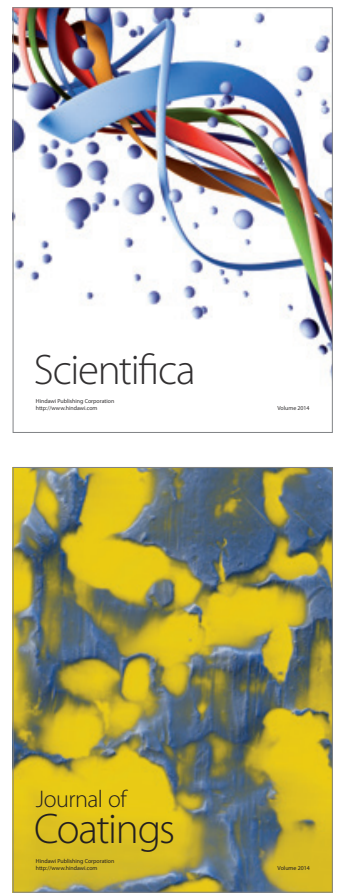
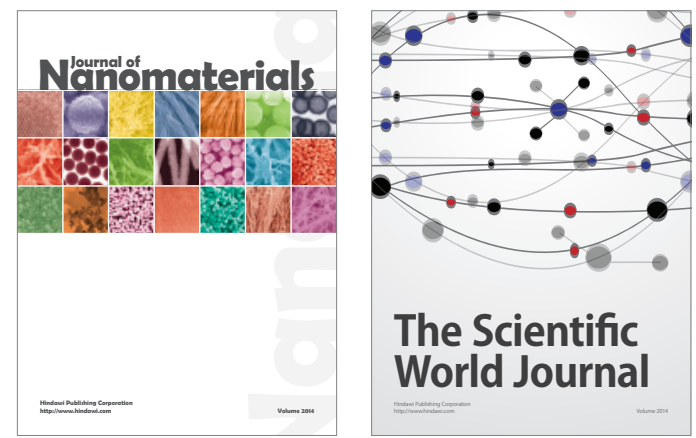

The Scientific World Journal
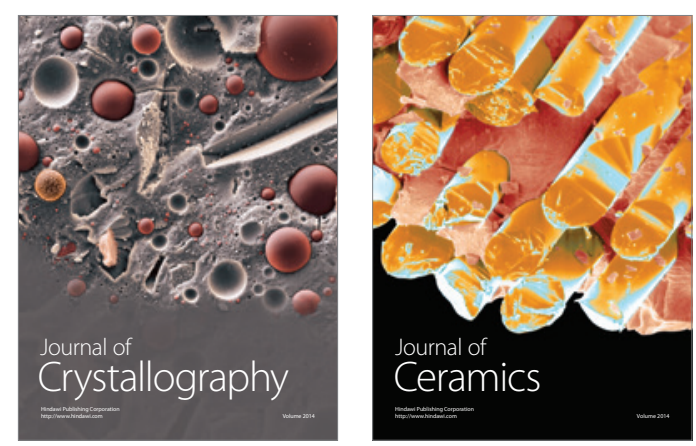
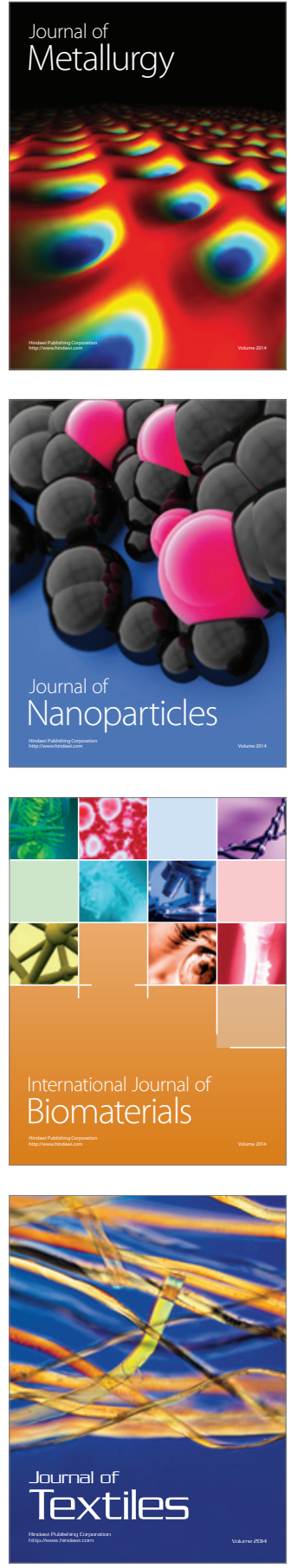